\title{
WILDLIFE ART AND ILLUSTRATION: MODELING IN FERROCEMENT - SOME EXPERIMENTS IN AUROVILLE, INDIA
}

\section{Eric Ramanujam ${ }^{1} \&$ S. Joss Brooks ${ }^{2}$}

Pitchandikulam Bioresource Centre / Pitchandikulam Forest Consultants, Auroville, Tamil Nadu 605101, India

${ }^{1}$ ericramanujamowl@yahoo.com (corresponding author), ${ }^{2}$ joss@auroville.org.in

Abstract: The differences between subtractive and additive three-dimensional sculpting are defined, along with the advantages of modeling. The various genres are highlighted and applications in the form of case studies presented as succinctly as possible. The empathy some artists have for particular media is also touched upon.

Keywords: Additive, animalier, animal sculpture, diorama, ferrocement, landscape architecture, modeling, subtractive.

\section{DOI: http://dx.doi.org/10.11609/JoTT.03975.6239-48}

Editor: Stephen D. Nash, Conservation International, Stony Brook, USA

Date of publication: 26 August 2014 (online \& print)

Manuscript details: Ms \# 03975 | Received 22 March 2014 | Finally accepted 07 July 2014

Citation: Ramanujam, M.E. \& S.J. Brooks (2014). Wildlife art and illustration: modeling in ferrocement - some experiments in Auroville, India. Journal of Threatened Taxa 6(9): 6239-6248; http://dx.doi.org/10.11609/JoTT.03975.6239-48

Copyright: (C Ramanujam \& Brooks 2014. Creative Commons Attribution 4.0 International License. JoTT allows unrestricted use of this article in any medium, reproduction and distribution by providing adequate credit to the authors and the source of publication.

Funding: Chennai Rivers Restoration Trust (CRRT), UNDP, Gulf of Mannar Biosphere Trust (GoMBRT) and Chennai Snake Park Trust (CSPT)

Competing Interest: The authors declare no competing interests.

Author Details: M. ERIC RAMANUJAM has been a wildlife illustrator for over two decades and has a background in the advertising industry. Since 1997 he has been involved in full time conservation and has been part of a team which undertook wildlife surveys in the Kaliveli region near Puducherry, Eastern Ghats and Adyar wetland complex in Chennai. His main sphere of interest is the natural history of the Indian Eagle Owl Bubo bengalensis. S. Joss Brooks established Pitchandikulam, a forest community in Auroville, and was one of the pioneers of re-establishing the indigenous coastal vegetation of the region. He was the lead consultant to the prestigious Government of Tamil Nadu's Adyar Poonga wetland restoration project in Chennai. He is the recipient of the Dr. Triloki Nath Khoshoo Award in $\mathbf{2 0 1 0}$ for his contribution to eco-restoration initiatives.

Author Contribution: MER prepared the manuscript with inputs from SJB.

Acknowledgements: We are thankful to Chennai Rivers Restoration Trust (CRRT), Gulf of Mannar Biosphere Reserve Trust (GoMBRT) and Chennai Snake Park Trust (CSPT) for giving us these opportunities and permission to use images of commissioned works.

\section{PITCHANDIKULAM}

FOREST 
Unlike subtractive carving, modeling techniques shape and build up form, and therefore offer the possibility of more detail, finesse and naturalistic rendition. In addition, there is not the ever-present threat of failure due to one single mistake which could irretrievably ruin a piece of work. This is a risk which hampers artistic expression in stone and wood carving, both involving subtractive techniques unlike modeling which require an additive approach.

Modeling in clay dates back to prehistoric times, for example, the European Bison Bison bonasus bull and cow in the 'Les Trois Freres' ('Cave of the Three Brothers' discovered in 1912 by Count Begouen and his three sons) in the Pyrenees dates back to the MidMagdalenian Period $(14,000 \mathrm{BC})$ when the world was still in an ice age that did not end until 8,000 BC (Bibby 1957).

Clay modeling in the ancient world was not as popular as stone sculpture, as in those times, the onus was on monumentalisation, rulers and priests ordering the creation of works proclaiming the power and might of their civilizations. Nevertheless, some clay models of animals exist from ancient Egypt, as the Egyptians often combined features from various creatures to symbolize ideas (Smith \& Simpson 2004).

To the Greeks, who perfected methods for producing maquettes for representation in stone, the human figure was the principal subject of the arts. Beginning in the late $7^{\text {th }}$ century BC, Greek sculptors sought better ways to represent the human figure, from that time onwards influencing many genres in the world of three-dimensional art (Cook 1986). It is surprising that even during the Renaissance, when clay became more popular, and as artists were freed from the burden of the hierarchical order and artists replaced the rigid form with a beauty that made sculpture more aesthetically pleasing, animal subjects were very rare (with the exception of horses - and that too with human association) (Snyder et al. 2004).

Though wax modeling evolved only during the Middle Ages $\left(5-15^{\text {th }}\right.$ century $\left.A D\right)$, it too went through a phase where no individual piece of animal art work seems to have been commissioned. During the Renaissance, and in spite of at least one of the old masters (Pisanello, also known as Antonio di Puccio Pisano and Antonio di Puccio da Cereto (1395-1455)), who was interested in wildlife subjects and created bronze medallions with human-animal motifs cast from wax models, very few actual examples are known.

It was not until the early $19^{\text {th }}$ century that animalthemed art came into its own and became accepted as a genre in its own right. Antecedents exist (how can one not be influenced by animal forms?), but a comparable degree of concentration on form and detail can be found only in the work of the English artist George Garrard (1760-1826) and he can actually be credited with being the first sculptor whose works are principally of animal subjects (Gilbey 1900). The beginnings of the acceptance of this genre can be attributed to the works of three sculptors: Antoine-Louis Barye, Christopher Fratin and Alexandre Guionnet, who exhibited their animal pieces at the Paris Salon in 1831. Their works were promptly derided by critics, and the derisive term 'Animalier' was coined (Anon 2002). Fortunately, at that time, the genre was given a boost by the much-publicized debate on comparative anatomy between Etienne Geoffroy de Saint Hilaire and his pupil Georges Cuvier which stimulated widespread interest in zoology, as did the growth in the popularity of the Jardin des Plantes where several generations of sculptors studied animals from life. In this sense, Paris could be considered to be the cradle of Animalier sculpture, transforming a derogatory phrase into a specialty which many sculptors were proud to practice (Griffiths 2013). Since that time the genre has become ever more prominent, and such esteemed names like Edwin Henry Landseer, Rembrandt Bugatti, Kenn Bunn, Bart Walters and Jonathan Kenworthy, have been associated with it.

Clay, wax and bronze all have their advantages, but at Pitchandikulam we were looking for an alternative as clay and wax are not suitable for the outdoor public spaces which characterize our facility, and bronze is too expensive. Ferrocement (also known as ferro concrete, reinforced concrete and steel-reinforced cement) was found to be an ideal choice for our purposes, since it has relatively good strength and impact resistance. Ferrocement is a mixture of cement and sand applied over an armature of closely spaced steel rods (called rebar or reba, which is the acronym for reinforcing bar) over which different sized woven or expanded steel meshes have been spread. Rebars, also known as reinforcing steel or reinforcement steel have been used as tension devices in reinforced masonary structures since at least the $18^{\text {th }}$ century - an example is the Leaning Tower of Nevyank in Russia (Fredric et al. 1995) which still stands today.

Not only have civil works benefitted from ferrocement, but also an interesting list of other applications. In fact, the trend can be accredited to two Frenchmen who used the medium for completely different purposes. Joseph-Louis Lambot (1814 - 1887) was an agriculturist who in 1841 started constructing 
water tanks and troughs using cement with iron reinforcement in the form of iron rods, chicken wire (invented in Britain in 1844) and barrel bands. In 1848 he constructed the first boat using the system which was patented in 1855 and presented at the Exposition Universelle (World's Fair) in Paris in the same year <en. wikipedia.org/wiki/Joseph-Louis Lambot>.

Joseph Monier (1823-1906) went on to develop Lambot's ideas regarding reinforced cement. He was a gardener who was not satisfied with materials used for making flowerpots-clay is brittle and wood weathered poorly and could also be broken by plant roots. He began making cement pots and tubs, but these proved not stable enough. In order to strengthen cement containers, he experimented with embedded iron mesh. He exhibited his inventions at the Paris Exposition in 1867 and obtained his first patent in the same year for iron-reinforced troughs for horticulture. Later he obtained more patents for iron-reinforced cement pipes and basins in 1868, reinforced cement panels for building facades in 1869, bridges made of ironreinforced concrete in 1873 and reinforced concrete beams in 1878 <en.wikipedia.org/wiki/Joseph Monier>.

In the 1930's through the 50's ferrocement became popular, not only for civil and other applications, but also for artistic rendering - like the 'dinosaurs in the desert' <en.wikipedia.org/wiki/Ferrocement> and the Cabazon dinosaurs <www.bigwaste.com/photos/ca/cabazon dinos>. One of the most famous of these pieces was a $13.8 \mathrm{~m}$ long building shaped like an Apatosaurus in Palm Springs, California that was used "by a new breed of creationist as pulpits to spread their version of Earth's origins" (Powers 2005). Claude Bell, the creator of this major work, will forever go down in history as the one who mattered the most to artists who work in this medium.

Pitchandikulam too has experimented extensively in the medium of ferrocement and some instances are discussed below.

\section{TYPES OF MODELS}

Life-sized models (Image 1): The aim here was to create life-sized replicas of living animals and juxtapose them with natural materials (specifically rocks and vegetation) to give an impression of these animals in their natural environment.

Scaled-up versions (Image 2): These were created to shock, and were designed to be rather grandiose. They were primarily used for outdoor public spaces and

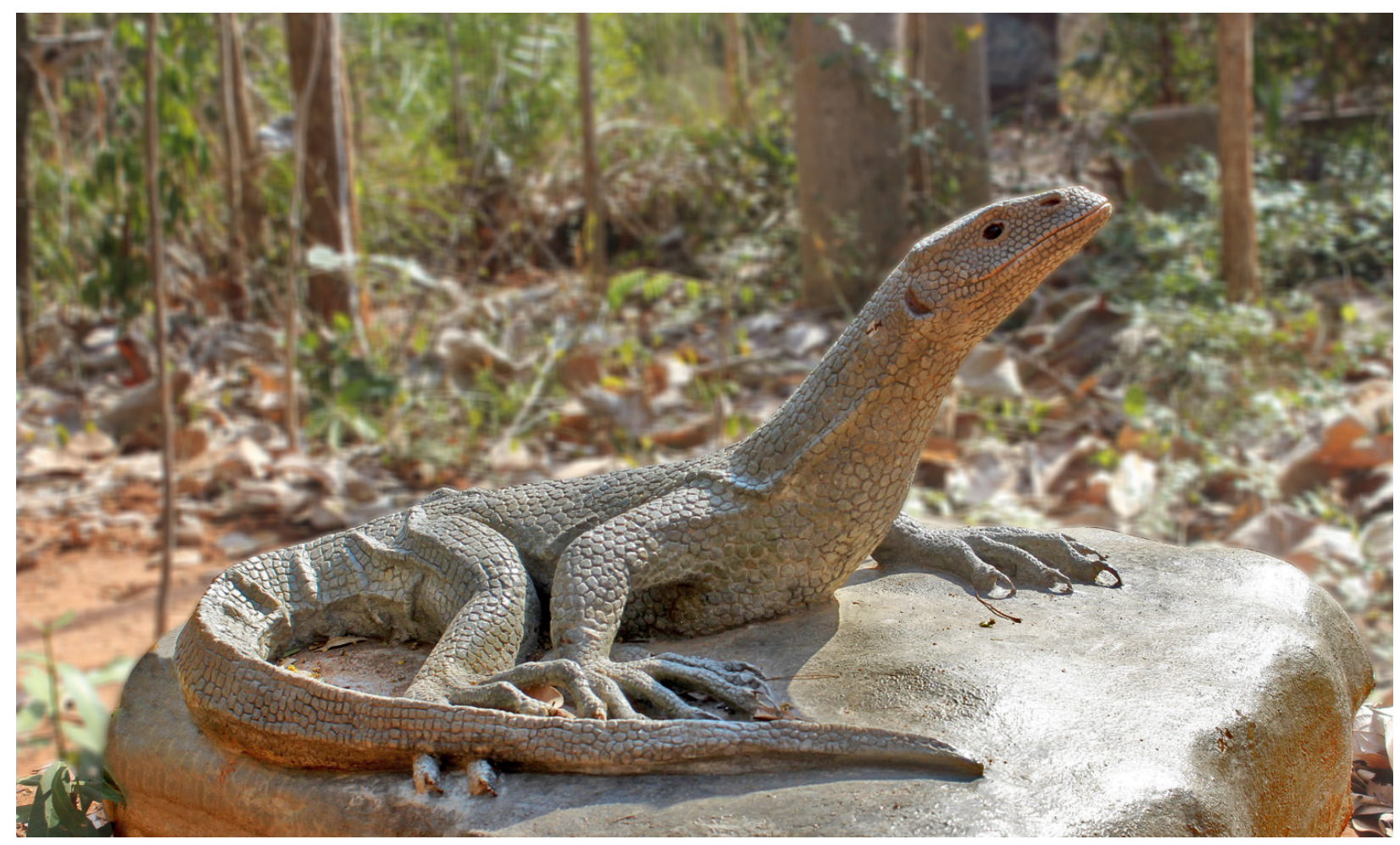

Image 1. A life-sized Indian Monitor Lizard Varanus bengalensis. The intention here was to create the texture and feel of the scaly skin with the characteristic folds in it. Only a little paint was used around the mouth, and the entire model covered with varnish. Pitchandikulam, Auroville. 


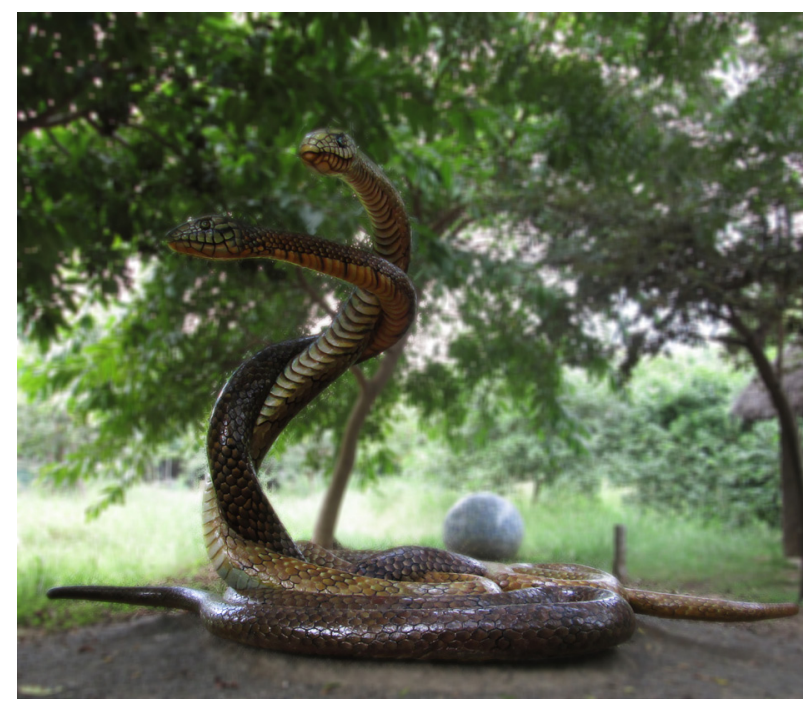

Image 2. Two rat snakes Ptyas mucosus in combat. This is a scaledup version approximately $3 \mathrm{~m}$ high. Adyar Eco Park, Chennai.

used to enhance landscape architecture. We have so far found scaled-down versions to be unsatisfactory as we have had trouble working with detail in this medium, especially when the subjects become too small. Unlike clay and beeswax, cement is not a very malleable

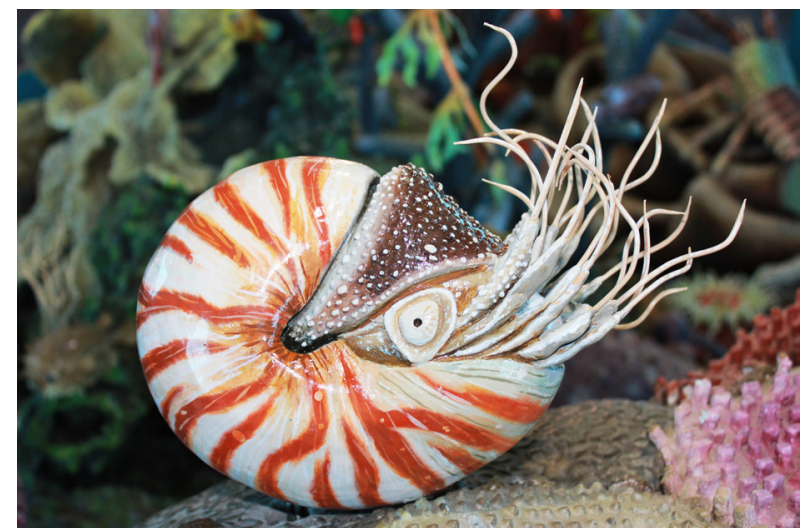

Image 3. Emperor Nautilus Nautilus pompilus. The tentacles were made out of wax and sealant (M Seal). Marine Interpretation Centre, Kundakal.

material and it is sometimes almost impossible to create minute detail and even if these can be created they are not very durable and wear away quickly if exposed to the elements.

Combining ferrocement with other materials (Images 3 \& 4): We have sometimes found it imperative to combine fabric, wax and sealant to produce different

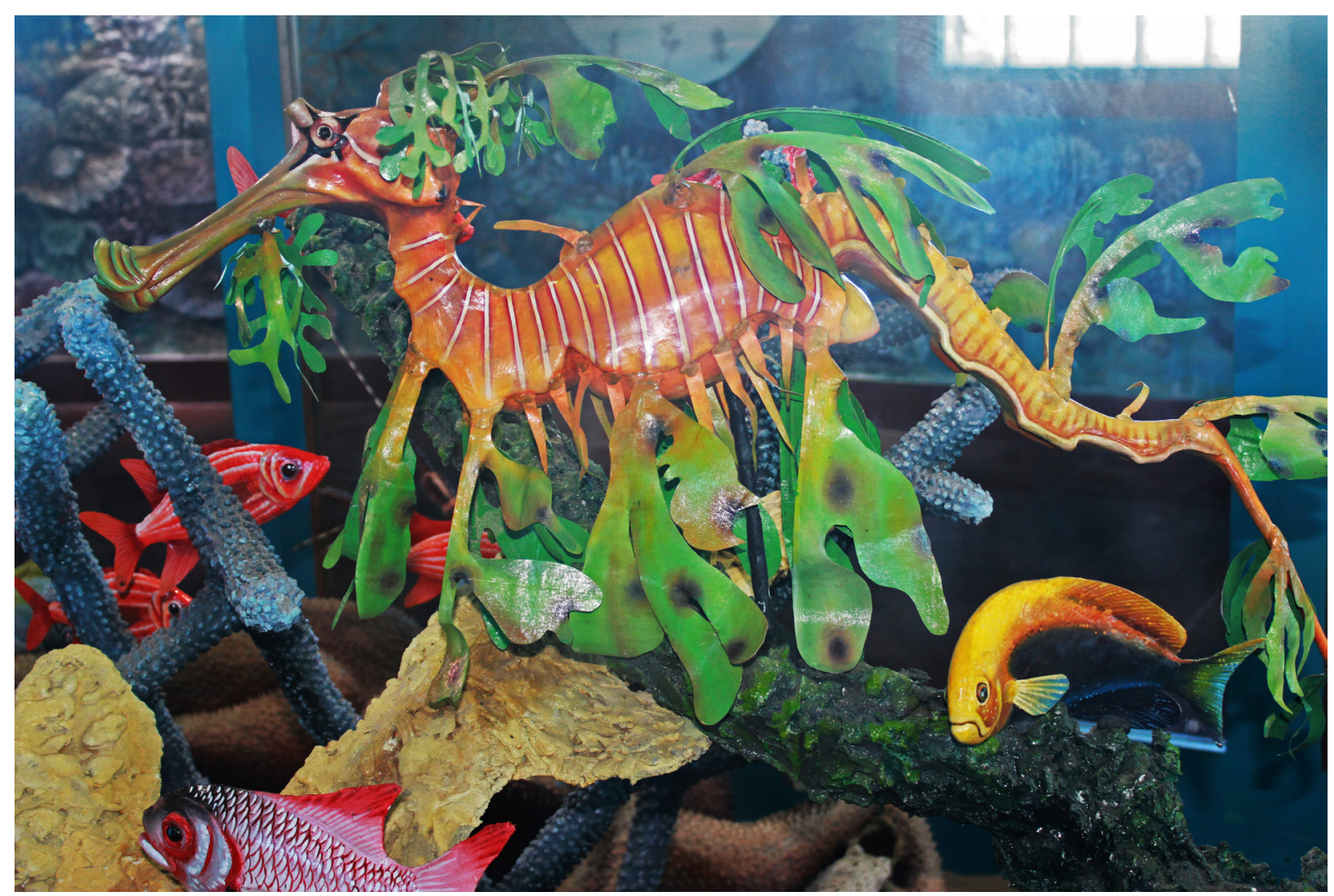

Image 4. Leafy Seadragon Phycodurus eques. The fins were made out of fabric. Marine Interpretation Centre, Kundakal. 
effects. For example, the use of fabric to represent fins of fishes was found to be quite convincing. Wax and sealant were used to create minute details like the tentacles of an anemone and of a Nautilus. However, these pieces cannot be displayed outdoors, nor can they be touchable by the public, as they are delicate, and can be easily damaged and hence need protection.

\section{APPLICATIONS OF MODELS}

Here we will attempt to give a few case histories of how we used the models for both entertainment value as well as an adjunct to conservation education.

Adyar Eco Park, Chennai (Images 5 \& 6): This was a laudable initiative by the Government of Tamil Nadu to develop an eco-park on a site which had been fundamentally misused. It was a 58-acre wetland area in the heart of Chennai City which had been degraded by decades of encroachment, pollution and general public apathy. In February 2007 the Government of Tamil Nadu decided to convert the area into the site of an eco rehabilitation programme. In consultation with the various governmental departments who played pivotal roles, the health of the ecosystem was improved by removing thousands of tons of rubble, pollution stopped from entering the site, illegal encroachment prevented, alien invasive Prosopsis juliflora and Eichhornia crassipes plants eradicated, and nearly 200,000 plants belonging to 173 species found in the coastal forests of this part of the country planted, in addition to over 30,000 mangroves belonging to seven species, which are all now self-seeding and ecologically sustainable. Today the area is a land of verdant green surrounding the water body and myriad life-forms have returned. At the last count there were 91 species of birds, including at times over a hundred spot- billed pelicans Pelecanus philippensis, more than 20 painted storks Mycteria leucocephala, and there was an unforgettable day when the then Deputy Chief Minister witnessed a White-bellied Sea Eagle Haliaeetus leugaster catch a fish at the western side of the site. This is an excellent example of a state government's initiative that can be a role model for the rest of the country and could help to dispel scepticism among the jaded naturalists inhabiting many cities in the vicinity of wetlands that once were quite dynamic and healthy. The park is open only to school children under supervision and it is planned that the site will be a centre for environmental education and is designed for that purpose. There is a fully-equipped education building with space for an auditorium, field laboratory and class rooms. Above all, however, it is envisaged that the park itself will be the key area, an outdoor classroom where children can experience nature in the heart of the city.

Art works are liberally spread all over the park in an

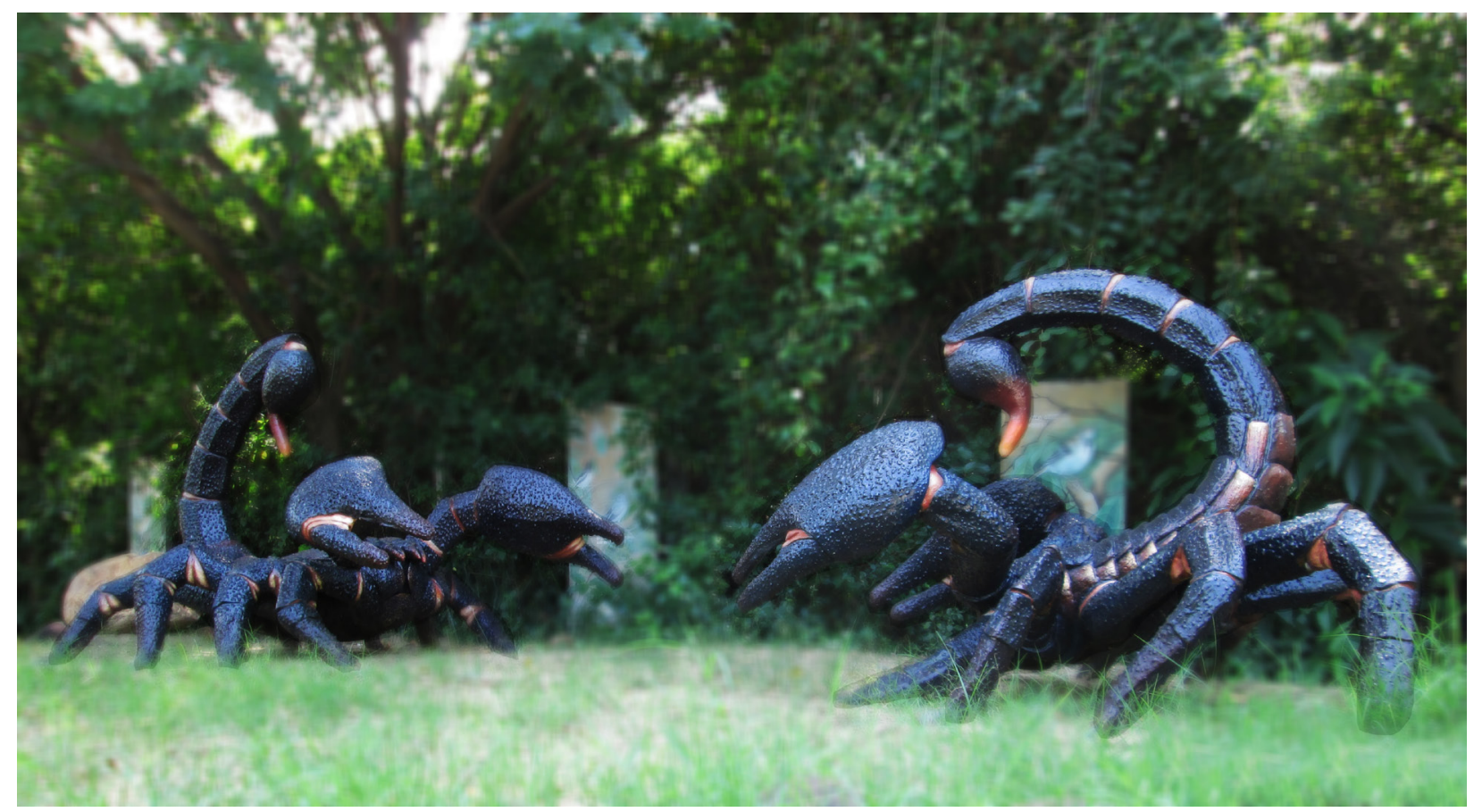

Image 5. Rock scorpions Heterometrus swammerdami facing each other. These are scaled-up versions approximately $3 m$ long each. Adyar Eco Park, Chennai. 


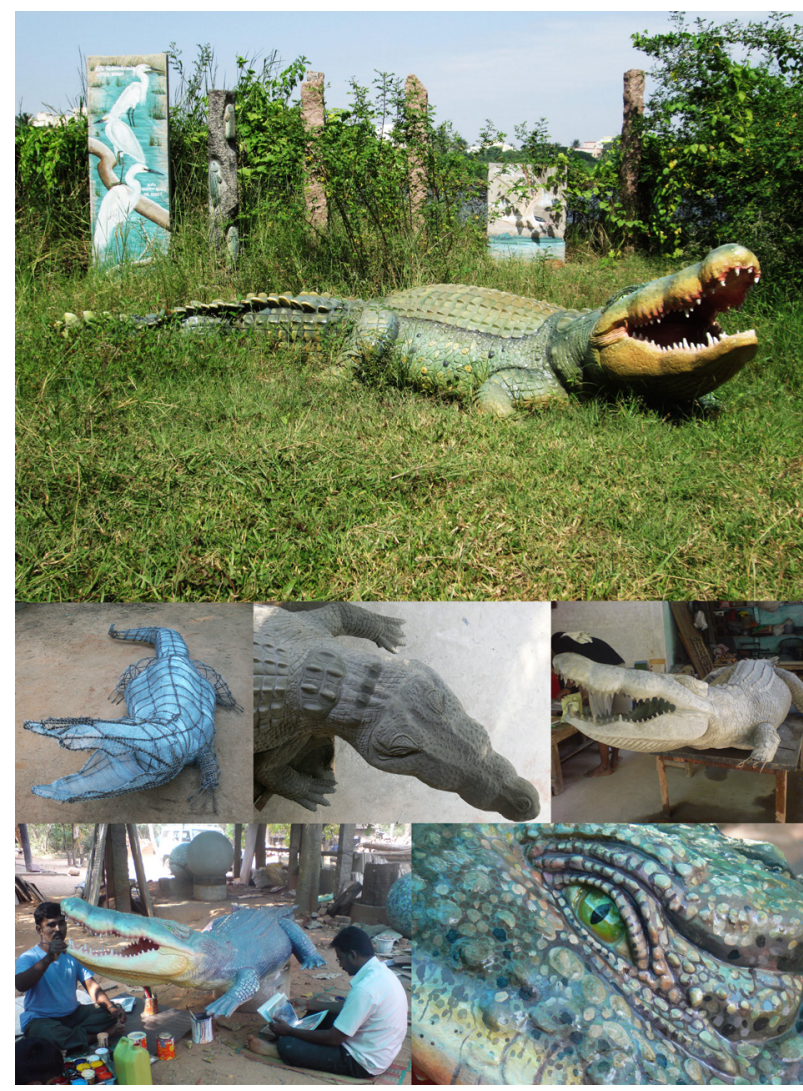

Image 6. Saltwater Crocodile Crocodylus porosus approximately $3.5 \mathrm{~m}$ long. Specimens over $5 \mathrm{~m}$ in length have been found in India (Daniel 2002). The insets depict the progress of the sculpture from the armature stage to the final painted detail. Adyar Eco Park, Chennai.

interactive way, and among them are both life-sized and scaled-up models of animals in ferrocement. At the entrance itself one is confronted by a scaled-up model of an Indian Monitor Lizard Varanus bengalensis, and elsewhere in the park the sculptures include a $3.7 \mathrm{~m}$ Saltwater Crocodile Crocodylus porosus basking on the bank of the wetland, two huge Rock Scorpions Heterometrus swammerdami duelling on a raised dais, a $1 \mathrm{~m}$ high Starred Tortoise Geochelone elegans in a sand dune garden and a $3 \mathrm{~m}$ high sculpture of two Rat Snakes Ptyas mucosus in combat, together with various snakes, bats and other creatures among the rafters of the education building. All the exhibits have been designed for outdoor public spaces, and the scaled-up versions can be touched and climbed upon by children, who find them fascinating.

Marine Interpretation Centre, Kundukal, near Rameswaram (Images 7 \& 8): This was a project undertaken in collaboration with the Gulf of Mannar Biosphere Reserve Trust and UNDP. The concept is that the visitor should have the impression of going underwater when entering the building, while at the same time being informed about marine life and the Gulf of Mannar Biosphere Reserve. Accordingly, the walls and ceiling are painted to replicate coral reefs and open waters replete with the creatures that inhabit them, and various interpretative signage erected. Life-sized models of a Dugong Dugong dugon with its young, and a Green Sea Turtle Chelonia mydas hang from the ceiling. The highlight and centerpiece of the space is an $5.8 \times 2.7$ $\mathrm{m}$ glass-enclosed diorama of a coral reef which can be viewed from all sides, with hundreds of associated life forms constructed out of ferrocement in combination with other materials.

Chennai Snake Park, Chennai (Images 9 \& 10): It was challenging and fascinating working on the models for the Chennai Snake Park Trust, due to the accuracy concerning form and detail which was necessary, and this required scientific supervision by qualified herpetologists. The finished product, however, was most satisfying. The project required the production of six glass-fronted dioramas representing herps (most of which were not on display in the park), or facets of behaviour that could not be observed in the reptiles exhibited there all the time. Examples of the former were species that were used to the cooler conditions of the Western Ghats, such as the King Cobra Ophiophagus hannah, Large-scaled Pit Viper Trimeresurus macrolepis, and Ornate Flying Snake Chrysopelea ornata. Facets of behaviour include an Indian Rock Python Python molurus, with eggs and young, and a Reticulated Python Python

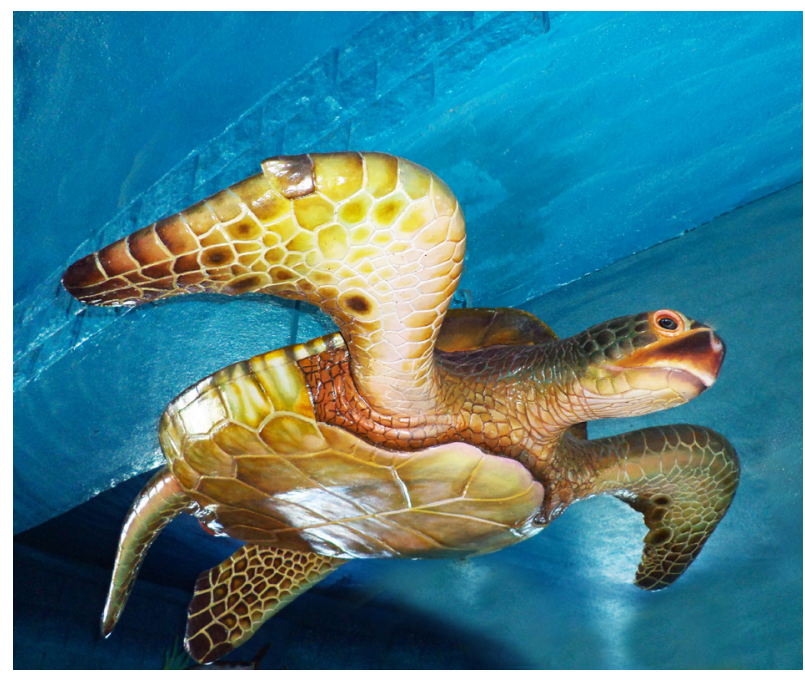

Image 7. Most people would imagine ferrocement to be very heavy, but, except for scaled-up models, most are not as heavy as imagined because they are hollow. Depicted here is a life-sized model of a Green Turtle Chelonia mydas hanging from the roof beam. Marine Interpretation Centre, Kundukal. 

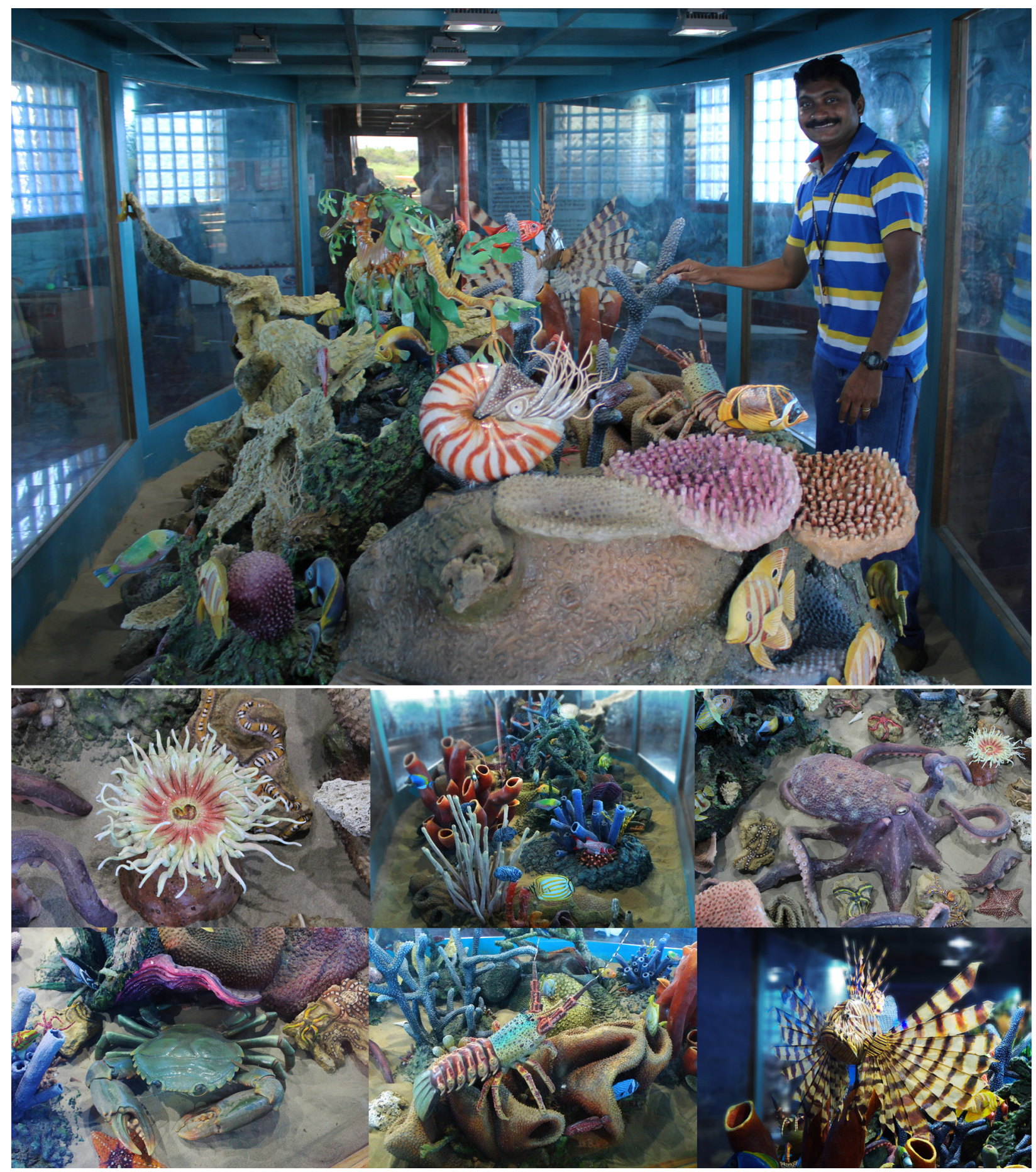

Image 8. Central diorama of a coral reef environment, with insets depicting various creatures contained in the exhibit. The exhibit is viewable from all sides and contains hundreds of sea creatures. The exhibit was designed to be impressive, and therefore many small life forms are enlarged beyond their natural size. Marine Interpretation Centre, Kundukal.

reticulata swallowing an Indian Muntjac Muntiacus muntjak-a real sense of dramatic representation was required for the latter two.

It may appear that we are promulgating the use of additive techniques over subtractive stone sculpture, but that is not our intention-in fact, we will continue to use both media, as they have their individual characteristics and intrinsic charm, and the subtractive techniques, being more demanding, are a constant challenge to the skill of the sculptor. Pitchandikulam 

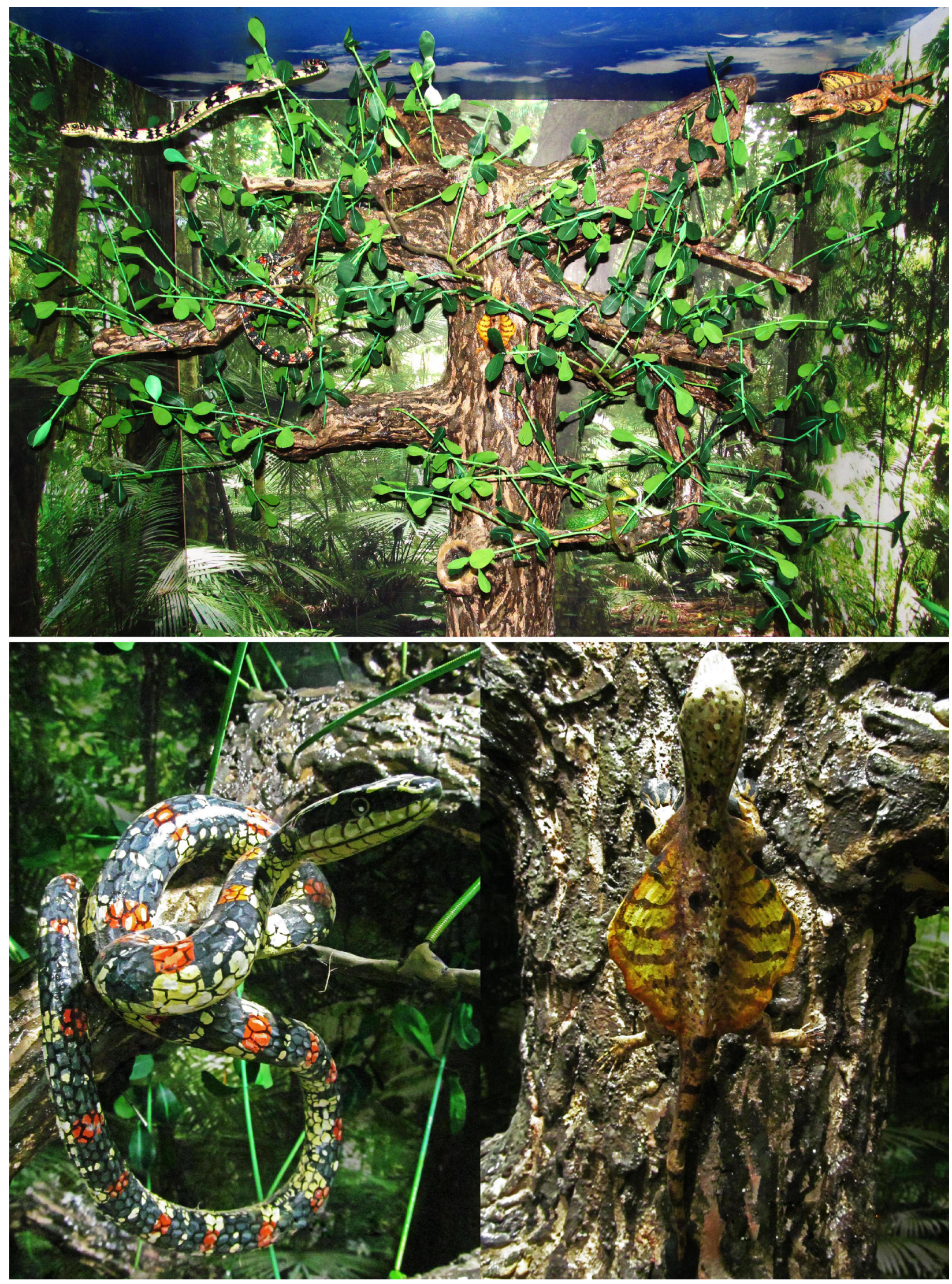

Image 9. A diorama with a Calophyllum austroindicum tree with flying lizards Draco dussumieri and ornate flying snakes Chrysopelea ornata, both in gliding mode and at rest, and a Large-scaled Pit Viper Trimerusurus macrolepis coiled up on one of its branches. Chennai Snake Park. 


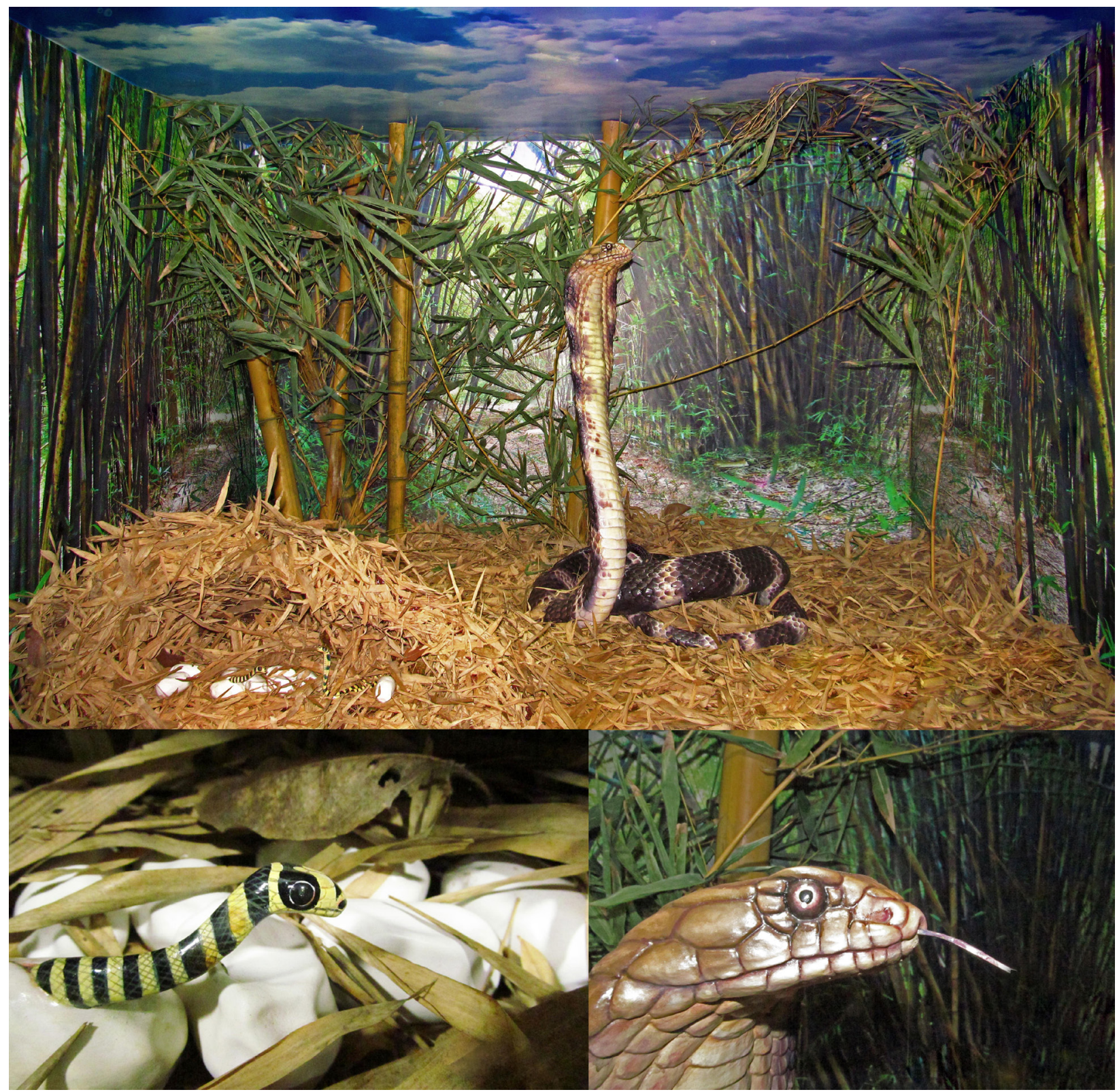

Image 10. A diorama of a King Cobra Ophiophagus hannah at the nest. A cross-section of the nest with eggs and two hatchlings can also be seen. The insets depict a young snake hatching out of an egg and a close up of the adult's head - the tongue was made with rubber. Chennai Snake Park.

has experimented with a variety of media, and a number of artists, and it has been enlightening to observe how some artists identify with certain media above others. We know, for example, an artist who was not very good at painting or drawing, but had an uncanny ability with modeling, and many of his works adorn the Marine Interpretation Centre-he has flourished and is doing quite well creating portrait busts and other such work. McLean (1960), writing about the distinguished wood engraver Joan Hassall, mentions "she had never tried wood engraving, nor even given a thought to it, until one day in 1931. At that time the School of Photo Engraving in Bolt Court, off Fleet Street, had a wood engraving class which was in danger of being closed due to lack of students: and Joan Hassall was persuaded by a fellow student to join the class to keep it open. From the moment she first handled the graver, it seemed to her like remembering, not learning, how to use it: she felt the cunning was in her hand already".

What is this phenomenon? How does it occur? We are far from understanding it, but a growing number of evolutionary biologists and anthropologists believe it 
could be responsible both for our physical and cultural evolution (Smets 1973; Balter 2009). Science still has a long way to go before it can hope to explain the emotional and subconciousness content that went into the making of a creature like Homo sapiens sapiens. All we can say for now is that visual art is the expression of an individual's journey, which is an evocation of feeling that cannot be put into words (Wilson 2012).

\section{REFERENCES}

Anonymous (2002). Dictionary of Art. Oxford University Press.

Balter, M. (2009). On the origin of art and symbolism. Science 323 : 709- 711.

Bibby, G. (1957). The testimony of the spade. Collins. 478 pp.

Cook, R.M. (1986). Greek Art: Its Development, Character and Influence. Penguin Books, 400pp.
Daniel, J.C. (2002). The Book of Indian Reptiles and Amphibians. Bombay Natural History Society and Oxford University Press, 240pp. Fredric, S.M., M.R. Loftin \& J.T. Ricketts (1995). Standard Handbook for Civil Engineers - th $^{\text {th }}$ Edition. McGraw Hill Book Company, 8-17pp. Gilbey, W. (1900). Animal Painters of England - From the Year 1650 - A brief history of their lives and works. Volume 1 - Monograph, 253pp. Griffiths, H.C. (2013). The Jury of the Paris Fine Art Salon, 1831-1852. Thesis. University of Exeter <http://hdl.handle.net/10871/12221>

McLean, R. (1960). The Wood Engravings of Joan Hassall. Oxford University Press, London, 38pp+188pl.

Powers, A. (2005). Adam, Eve and T. Rex. Los Angeles Times. December 11-14.

Smets, G. (1973). Aesthetic Judgement and Arousal: An Experimental Contribution to Osycho-Aesthetics. Leuven University Press, Belgium, 106pp.

Smith, W.S. \& W.K. Simpson (2004). The Art and Architecture of Ancient Egypt. Journal of Near Eastern Studies 63: 148-149.

Snyder, J., L. Silver \& H. Luttikhuizen (2004). Northern Renaissance Art. Harry N. Abrams, 592pp.

Wilson, E.O. (2012). The Social Conquest of Earth. Liveright Publishing Corporation, New York, 330pp. 